\title{
STRATEGI PENGEMBANGAN TEKNOLOGI E-COMMERCE UMKM RUMAH SAYUR LEMBANG MENGGUNAKAN METODE ANALISIS SWOT
}

\author{
Bahtiar Gunawan'), Maulana Shaleh" ${ }^{2)}$, Nisrina Anbar ${ }^{3)}$, Rangga Sanjaya ${ }^{4)}$ \\ ${ }^{1}$ Fakultas Teknologi Informasi, Universitas Adhirajasa Reswara Sanjaya \\ Jl. Sekolah Internasional No. 1-2, Antapani, Bandung \\ email: bahtiargun221@gmail.com \\ ${ }^{2}$ Fakultas Teknologi Informasi, Universitas Adhirajasa Reswara Sanjaya \\ Jl. Sekolah Internasional No. 1-2, Antapani, Bandung \\ email: maulshalehm@gmail.com \\ ${ }^{3}$ Fakultas Teknologi Informasi, Universitas Adhirajasa Reswara Sanjaya \\ J1. Sekolah Internasional No. 1-2, Antapani, Bandung \\ email: nisrina.anbar28@gmail.com \\ ${ }^{4}$ Fakultas Teknologi Informasi, Universitas Adhirajasa Reswara Sanjaya \\ Jl. Sekolah Internasional No. 1-2, Antapani, Bandung \\ email: rangga.rsj@gmail.com
}

\begin{abstract}
The research aims to identify the fundamental potential information of internal and external factors that determinant strategies that can be used in strategy development. The development of Micro, Small and Medium Enterprises (UMKM) Rumah Sayur impresses slowly, because of the missed in ecommerce technology in its business. Cause a lack of opportunities to be able to compete in the business world. There needs to be a system development strategy to run and develop well. One of the ways that can be done to help determine an e-commerce technology system development strategy is to conduct a SWOT analysis. SWOT analysis is necessary to know the strengths and weaknesses as well as opportunities and threats to the company or business to face strict competition as well as to give competitiveness among Micro, Small and Medium Enterprises (UMKM). The results of the analysis describe the analysis of the internal business factors and the company's e-commerce technology system as well as the external factors of business and the Micro, Small and Medium Enterprises (UMKM) e-commerce technology system Rumah Sayur. Data collection techniques in this study using the method of literature study, observation, interviews, and questionnaires. The questionnaire used consisted of four questions related to factors of strength, weakness, opportunity, and threat, for target respondents namely the manager of Micro, Small and Medium Enterprises (UMKM) Rumah Sayur such as the head of commodities, CMO, farmer Coordinator, and marketing department. From the results of the analysis, the calculation of matrix IFAS and EFAS shows that the strength is greater than weakness and opportunity greater than the threat and it can be concluded that Micro, Small and Medium Enterprises (UMKM) Rumah Sayur need to take policy aggressive strategy to develop e-commerce technology given the high strength and opportunity in the middle of existing Micro, Small and Medium Enterprises (UMKM) competition.
\end{abstract}

Keywords: Internal Factors, External Factors, Existing Micro, Small and Medium Enterprises (UMKM), E-Commerce Technology, SWOT Analysis

\begin{abstract}
Abstrak
Penelitian ini bertujuan untuk mengidentifikasi informasi potensi dasar faktor-faktor internal dan eksternal penentu strategi yang dapat digunakan dalam pengembangan strategi. Perkembangan UMKM Rumah Sayur terkesan lambat, karena ketinggalan dalam teknologi e-commerce di dalam usahanya. Menyebabkan sangat minimnya peluang untuk mampu bersaing di dunia usaha. Perlu adanya strategi pengembangan sistem supaya dapat berjalan dan berkembang dengan baik. Salah satu cara yang dapat dilakukan untuk membantu menentukan strategi pengembangan sistem informasi adalah dengan melakukan analisis SWOT. Analisis SWOT diperlukan untuk mengetahui
\end{abstract}


kekuatan dan kelemahan serta peluang dan ancaman bagi perusahaan atau usaha untuk menghadapi persaingan yang ketat sekaligus meningkakan daya saing antar sesama UMKM. Hasil dari analisis tersebut menjabarkan terkait analisis faktor internal bisnis dan Sistem teknologi e-commerce perusahaan serta faktor eksternal bisnis dan Sistem teknologi e-commerce UMKM Rumah Sayur. Teknik pengumpulan data dalam penelitian ini menggunakan metode studi pustaka, observasi, wawancara, dan kuesioner. Kuesioner yang digunakan terdiri dari empat pertanyaan terkait dengan faktor kekuatan, kelemahan, peluang, dan ancaman, untuk target responden yaitu pengelola UMKM Rumah Sayur seperti ketua komoditas, CMO, koordinator petani, dan bagian pemasaran. Dari hasil analisis, perhitungan matriks IFAS dan EFAS menunjukkan bahwa kekuatan lebih besar dari kelemahan dan peluang lebih besar dari ancaman dan dapat disimpulkan bahwa UMKM Rumah Sayur perlu mengambil kebijakan strategi agresif dalam rangka pengembangan teknologi ecommerce mengingat kekuatan dan peluang yang tinggi ditengah persaingan UMKM yang saat ini sudah banyak.

Kata kunci: Faktor Internal, Faktor Eksternal, UMKM, Teknologi E-Commerce, Analisis SWOT

\section{PENDAHULUAN}

Perkembangan UMKM (Usaha Mikro Kecil dan Menengah) di berbagai daerah di Indonesia semakin berkembang pesat [1]. Setelah terjadinya krisis ekonomi di Indonesia pada tahun 1997 hingga 1998, sektor UMKM mampu untuk tetap berdiri kokoh. Data Badan Pusat Statistik mengungkapkan bahwa setelah terjadinya krisis ekonomi jumlah UMKM di Indonesia tidak berkurang, justru pertumbuhannya semakin meningkat, bahkan sampai tahun 2012 mampu menyerap 85 juta hingga 107 juta tenaga kerja. Pada tahun itu terdapat 56.539.560 unit pengusaha yang ada di Indonesia. Dari jumlah tersebut, ada sebesar 99,99\% atau sekitar 56.534.592 unit UMKM. Sisanya sekitar 0,01\% atau sebesar 4.968 unit. Dan sampai sekarang pun sudah banyak UMKM berkembang di Indonesia baik usaha yang berskala kecil mau pun berskala besar [1].

UMKM berpotensi untuk menanggulangi kemiskinan, jika sektor UMKM dikembangkan. UMKM memiliki andil yang besar dalam penyerapan tenaga kerja yaitu lebih dari 99,45\% dan sumbangan terhadap Pendapatan Domestik Bruto (PDB) kurang lebih $30 \%$. Akan menyerap lebih banyak lagi tenaga kerja jika ada upaya untuk mengembangkan dan memajukan sektor UMKM, dan tentu saja dengan cara tersebut para pekerja yang terlibat di dalamnya dapat meningkat kesejahteraannya sehingga angka pengangguran pun berkurang [1].

Salah satu faktor yang mendukung berkembangnya UMKM di Indonesia adalah peranan teknologi informasi. Karena bisa membuat peluang pasar terbuka lebih luas jika menerapkan teknologi infomasi dalam berbisnis. Berbisnis melalui internet dapat mempermudah dalam mempromosikan produk kepada konsumen atau pelanggan [2]. Menurut data dari Badan Pusat Statistik (BPS) hanya 75 ribu dari 17 juta UMKM yang tersebar di Indonesia yang menggunakan teknologi informasi, sehingga kesempatan pasar di dunia digital belum mereka raih sepenuhnya. Sedangkan, berdasarkan survey yang telah dilakukan terhadap 200 pelaku UMKM di Indonesia baru-baru ini, pada umumnya 29\% dari penghasilan mereka setiap tahunnya diperoleh dari transaksi online. [3]

Salah satu UMKM yang berada di Cisarua Lembang, Jawa Barat, yaitu UMKM Rumah Sayur. UMKM Rumah Sayur ini bergerak dalam sektor pertanian, yang menghasilkan berbagai produk unggulan sayuran-sayuran yang segar, Rumah Sayur ini mendistribusikan sayuran-sayuran tersebut ke berbagai tempat seperti supermarket, tempat makan, dan sebagainya. Perkembangan UMKM Rumah Sayur ini terkesan lambat, hal tersebut terjadi karena tertinggalnya teknologi informasi di dalam usaha mereka. Sehingga 
banyak terjadi kendala seperti kurangnya kualitas marketing, stok yang tidak real time, pengiriman yang cenderung bermasalah, dan pengelolaan keuangan yang tidak mendetail.

Menyikapi hal di atas, salah satu penyelesaiannya yaitu UMKM harus bisa beradaptasi terhadap perkembangan zaman yang semakin maju dan canggih serta perlu difasilitasi dengan optimalisasi perangkat lunak dan sistem informasi [4]. Karena kemajuan informasi dan teknologi di era seperti sekarang ini sangat pesat, dan telah mendorong kita untuk mempersiapkan diri masuk menjadi bagian aktif dari masyarakat ekonomi-informasi di dunia usaha. Kondisi tersebut menjadikan semakin terbuka tanpa batasnya pasar dan perdagangan yang ada, sehingga antara pelaku-pelaku bisnis yang berasal dari semua kalangan, memiliki peluang yang sama atau setara, dia yang cepat maka dia yang akan dapat atau dikenal dengan istilah time-to-market atau economic time [5].

Perlu adanya strategi pengembangan sistem, supaya sistem teknologi e-commerce dapat berjalan dan berkembang dengan baik [6]. Salah satu cara yang dapat dilakukan untuk membantu menentukan strategi pengembangan sistem informasi adalah dengan melakukan analisis SWOT, karena dengan menggunakan analisis SWOT perusahaan dapat melakukan evaluasi kinerja dengan mudah, perkembangan untuk pengukuran SWOT sangatlah baik, sudah banyak perusahaan atau organisasi yang menggunakan analisis SWOT untuk mencari dan mendapatkan strategi pengembangan kinerja usahanya [7]. Analisis SWOT diperlukan untuk mengetahui kekuatan dan kelemahan serta peluang dan ancaman bagi perusahaan atau usaha untuk menghadapi persaingan yang ketat sekaligus meningkatkan daya saing antar sesama UMKM [8]. Dimana untuk mengoptimalkan penjualan dan pemasaran perlu diterapkannya strategi agar memenangkan persaingan yaitu dapat melalui faktor eksternal dan faktor internal suatu perusahaan [9]. Harapannya, hasil analisis tersebut bisa membantu UMKM Rumah Sayur dalam menentukan strategi yang cocok agar strategi yang disesuaikan dengan visi misi dan proses bisnis, serta dapat dilaksanakan secara maksimal dan komprehensif. Diharapkan penelitian ini mendapatkan hasil yang dapat memberikan manfaat dalam pengarahan perencanaan strategi teknologi e-commerce sehingga sesuai dengan strategi bisnis.

\section{TINJAUAN PUSTAKA}

\subsection{Analisis $S W O T$}

Metode analisis SWOT merupakan suatu metodologi untuk mencari hubungan antara peluang dan ancaman eksternal perusahaan, dengan kekuatan dan kelemahan internal perusahaan. [9]

Fungsi dari analisis SWOT dan strategi kompetitif adalah untuk menganalisis mengenai kelemahan, kekuatan dan keunggulan kompetitif yang dimiiki suatu usaha/perusahaan, yang dilakukan melalui analisis terhadap kondisi internal, dan dilakukan melalui analisis terhadap kondisi eksternal perusahaan mengenai peluang dan ancaman yang dihadapi perusahaan [10]. 


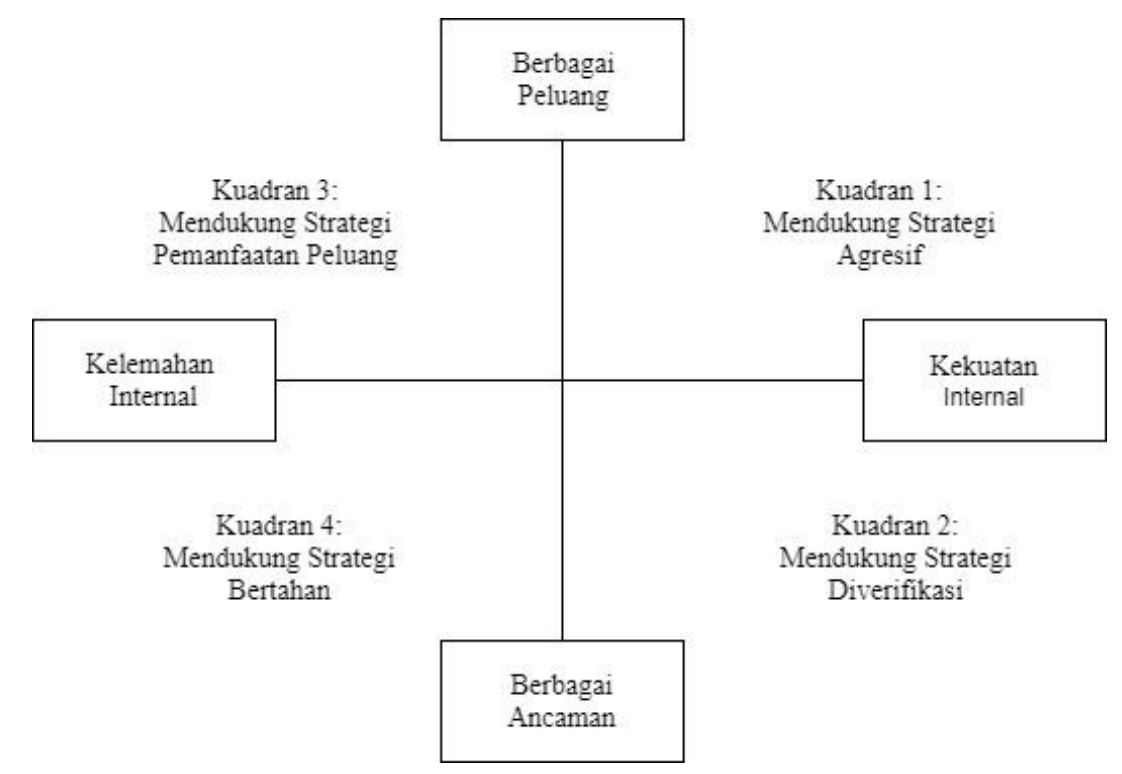

Sumber: [11]

\section{Gambar 1. Diagram SWOT}

1. Kekuatan (Strengths)

Keunggulan-keunggulan atau keterampilan, relatif terhadap pesaing atau kebutuhan pasar.

2. Kelemahan (Weaknesses)

Keterbatasan atau kerurangan dalam sumber daya, keterampilan yang menghambat efektifitas perusahaan.

2. Peluang (Opportunity)

Situasi penting yang memberi keuntungan bagi perusahaan.

3. Ancaman (Threats)

Situasi yang tidak memberi keuntungan dalam lingkungan perusahaan.

\subsection{Matriks SWOT}

Matriks SWOT merupakan alat strategi yang dapat membantu perusahaan untuk menggambarkan penyesuaian antara peluang dan ancaman ekternal (EFAS) yang dihadapi dengan kekuatan dan kelemahan (IFAS) suatu perusahaan, serta untuk melihat alternatif strategi apa yang sesuai dan dapat diterapkan, yang dimiliki suatu perusahaan berdasarkan 4 tipe strategi [12] yaitu :

1. Strategi SO (Strength-Opportunities)

Strategi ini dibuat berdasarkan pemikiran perusahaan, yaitu dengan cara memanfaatkan kekuatan yang dimiliki perusahaan untuk meraih peluang-peluang yang ada.

2. Strategi ST (Strenghts-Threats)

Strategi dalam menngunakan kekuatan untuk meminimalisir atau mengurangi ancamanancaman eksternal.

3. Strategi WO (Weknesses-Opportunities)

Strategi ini diterapkan dengan memanfaatkan peluang-peluang yang ada untuk meminimalisiratau mengurangi kelemahan-kelemahan suatu perusahaan.

4. Strategi WT (Weknesses-Threats) 
Strategi ini untuk meminimalisir kelemahan serta menghindari ancaman terhadap perusahaan.

Langkah-langkah pembuatan matrix SWOT [12], yaitu :

1. Menentukan faktor-faktor kekuatan internal dan masukkan ke dalam kolom Strength (S)

2. Menentukan faktor-faktor kelemahan internal dan masukkan ke dalam kolom Weakness (W)

3. Menentukan faktor-faktor peluang eksternal dan masukkan ke dalam kolom Opportunity (O)

4. Menentukan faktor-faktor ancaman eksternal dan masukkan ke dalam kolom Threat (T)

5. Hubungkan kekuatan internal (S) dan peluang eksternal (O), kemudian jelaskan strategi yang dapat diterapkan pada kolom Strenght-Opportunity (SO)

6. Hubungkan kelemahan internal (W) dan peluang eksternal (O), kemudian jelaskan strategi yang dapat diterapkan pada kolom Weakness-Opportunity (WO)

7. Hubungkan kekuatan internal (S) dan ancaman eksternal (T), kemudian jelaskan strategi yang dapat diterapkan pada kolom strategi Strengt-Threat (ST)

8. Hubungkan kelemahan internal (W) dan ancaman eksternal (T), kemudian jelaskan strategi yang dapat diterapkan pada kolom strategi Weakness-Threat (WT)

Tabel 1. Tabel Matriks SWOT

\begin{tabular}{l|l|l}
\hline \multicolumn{1}{c|}{ IFAS } & $\begin{array}{l}\text { S (Strength) } \\
\text { Tentukan Faktor-faktor } \\
\text { Kekuatan Internal }\end{array}$ & $\begin{array}{l}\text { W (Weakness) } \\
\text { Tentukan Faktor-faktor } \\
\text { Kelemahan Internal }\end{array}$ \\
EFAS & $\begin{array}{l}\text { Strategi SO : } \\
\text { Ciptakan strategi dari } \\
\text { kekuatan yang dimiliki untuk } \\
\text { memanfaatkan peluang }\end{array}$ & $\begin{array}{l}\text { Ciptakan strategi yang } \\
\text { meminimalisir kelemahan } \\
\text { untuk memanfaatkan } \\
\text { peluang }\end{array}$ \\
\hline $\begin{array}{l}\text { Tentukan Faktor-faktor } \\
\text { Peluang Eksternal }\end{array}$ & $\begin{array}{l}\text { Strategi WT : } \\
\text { Ciptakan strategi yang } \\
\text { meminimalisir kelemahan } \\
\text { dan menghindari ancaman }\end{array}$ \\
\hline $\begin{array}{l}\text { T (Threat) } \\
\text { Tentukan Faktor-faktor }\end{array}$ & $\begin{array}{l}\text { Ciptakan strategi dari } \\
\text { kekuatan yang dimiliki untuk } \\
\text { mengatasi ancaman }\end{array}$ & \multicolumn{2}{|l}{} \\
\hline
\end{tabular}

Sumber : [13]

\subsection{Perhitungan Matriks IFAS dan EFAS}

Perhitungan IFAS digunakan untuk mengevaluasi faktor-faktor yang ada pada lingkungan internal berupa kelemahan dan kekuatan yang dimiliki perusahaan. Perhitungan EFAS digunakan untuk mengevaluasi faktor-faktor yang berpengaruh pada objek penelitian yang ada di luar lingkungan perusahaan berupa ancaman dan peluang, dalam membuat matriks EFAS ini perlu mengevaluasi dan mengetahui lingkungan eksternal perusahaan, baik lingkungan industri maupun lingkungan umum [11].

Kelebihan dari perhitungan Matriks IFAS dan EFAS yaitu dapat dengan mudah dalam melakukan evaluasi pekerjaan, dan terbukti sangat bermanfaat dalam memahami lingkungan organisasi atau perusahaan, dan dalam perencanaan strategi pertumbuhan dan perkembangannya, sedangkan kekurangannya yaitu tidak dapat mengukur efek dari berat dan faktor strategis pada alternatif [14]. Berikut ini merupakan tahap dari penentuan matriks IFAS dan EFAS [15]:

a. Tahap Penentuan Strategi Internal (IFAS) 
1. Pada tahap awal, tentukan faktor-faktor kekuatan dan kelemahan pada perusahaan dan masukkan pada kolom I

2. Masukkan tiap bobot pada faktor kekuatan dan kelemahan berdasarkan pengaruh faktor-faktor tersebut terhadap posisi strategi organisasi, yang dimulai dari skala 0 (tidak penting) sampai skala 1 (sangat penting). Jumlah semua bobot tidak boleh melebihi dari skor total $=1,00$.

3. Hitunglah rating untuk masing-masing faktor tersebut, berdasarkan pengaruh faktor yang ada terhadap kondisi organisasi, yang dimulai dari skala 0 (tidak penting) sampai skala 4 (sangat penting). Berilah nilai 1 sampai 4 pada variabel yang masuk kedalam kategori kekuatan (bersifat positif), dengan membandingkan rata-rata pesaing utama. Selain itu pada variabel yang masuk ke dalam kategori kelemahan (bersifat negative), seperti contoh: juka organisasi memiliki kelemahan dibandingkan dengan rata-rata pesaingnya, maka dapat diberi bobot nilai 1 dan apabila kelemahan organisasi dibawah rata-rata dibandingkan dengan rata-rata pesaingnya, maka diberi bobot nilai 4 .

b. Tahap Penentuan Strategi Eksternal (EFAS)

1. Masukkan faktor-faktor peluang dan ancaman pada 1 kolom.

2. Kemudian faktor-faktor tersebut memungkinkan dapat memberikan dampak terhadap faktor strategi dengan memberikan bobot nilai, yang dimulai dari skala 0 (tidak penting) sampai skala 1 (sangat penting).

3. Masing-masing faktor diberikan bobot nilai 4 (outstanding) sampai dengan skala 1 (poor) untuk menghitung rating pencapaian atau pengaruh faktor terhadap kondisi organisasi. Berikut penjabaran positif negative pada bobot nilai rating. Nilai positif (jika peluang semakin besar, maka diberi bobot nilai rating 4. Namun jika peluangnya kecil maka diberi bobot nilai rating 1). Berikut untuk pemberian bobot nilai rating ancaman, apabila nilai ancaman sangat besar maka bobot nilai rating 1 . Sebaliknya, jika nilai ancaman kecil maka bobot nilai rating 4 .

4. Kemudian hitung bobot rating dengan cara mengkalikan bobot dengan rating, untuk memperoleh faktor pembobotan. Hasilnya berupa skor pembobotan dari masingmasing faktor (dari skala 4,0 untuk outstanding sampai dengan 1,0 untuk poor).

5. Kemudian jumlahkan skor pembobotan untuk memperoleh total skor pembobotan guna organisasi tersebut (pada kolom 4). Nilai dari hasil penjumlahan skor menunjukkan bagaimana organisasi bereaksi terhadap faktor-faktor strategis eksternal

\subsection{Definisi E-Commerce}

Menurut Andi dalam [6] e-commerce yaitu kegiatan membeli atau menjual secara elektornik yang dilakukan pada jaringan internet. Electronic Commerce (EC) juga berarti penggambaran proses pembelian, penjualan, transfer, pertukaran barang atau informasi yang dilakukan melalui jaringan computer termasuk internet. [6]

\subsection{Teknologi Yang Diperlukan Dalam E-Commerce}

UMKM yang sudah memanfaatkan teknologi e-commerce salah satunya yaitu UMKM kain tenun songket Palembang. Peranan dari teknologi e-commerce dalam UMKM ini sangatlah besar, khususnya dalam efisiensi pekerjaan dan penunjang proses pemasaran, dan dapat membuka peluang pasar lebih luas lagi. Dengan memanfaatkan teknologi ecommerce maka UMKM dapat bersaing dengan UMKM lainnya, dapat bersaing di tingkat Nasional maupun Internasional [16]. 
UMKM lain yang sudah menerapkan teknologi e-commerce yaitu UMKM sektor fashion di wilayah Jakarta, dengan menerapkan teknologi e-commerce UMKM dapat menunjang kegiatan pemasaran secara online. Strategi ini dapat meningkatkan kecepatan, intensif, dan mengurangi biaya hubungan pelaku bisnis dengan pemasok, distributor, konsumen dibandingkan dengan cara konvensional. Dan mendapatkan peluang ekspor dan bisnis lainnya dengan memanfaatkan teknologi e-commerce [17]. meliputi :

Perkembangan teknologi e-commerce memerlukan keterpaduan aplikasi [6], yang

1. Transakasi Online

fasilitas yang disediakan situs e-commerce kepada konsumen untuk bisa melakukan order atau pembelian barang atau produk secara online.

2. Katalog Online

Informasi barang atau produk yang diberikan kepada konsumen.

3. Status Order

Untuk mengetahui sampai dimana transaksi yang sudah dilakukan telah diproses oleh penyedia situs e-commerce ketika konsumen telah melakukan transaksi online.

\section{METODE PENELITIAN}

Penelitian ini dilakukan di UMKM Rumah Sayur Lembang, lebih tepatnya berada di Jl. Cipeusing, Cisarua, Kecamatan Cisarua, Kabupaten Bandung Barat.

Jenis penelitian yang digunakan yaitu penelitian deskriptif kualitatif. Penelitian latar belakang alamiah digunakan dalam penelitian deskriptif, dengan maksud menganalisis fenomena yang sedang terjadi dan dilakukan dengan mengikutsertakan berbagai metode yang ada [18]. Kuesioner berisi variabel yang berkenaan kondisi internal dan kondisi eksternal UMKM Rumah Sayur.

Skala likert digunakan untuk memberikan nilai pada setiap peryataan kuesioner. Pemberian nilai 4 diberikan jika pernyataan kuesioner memiliki tingkat sangat setuju. Sampai pemberian nilai 1, jika pernyataan kuesioner memiliki tingkat tidak setuju.

Alur Metodologi penelitian dalam penelitian ini dapat dilihat pada Gambar 2.

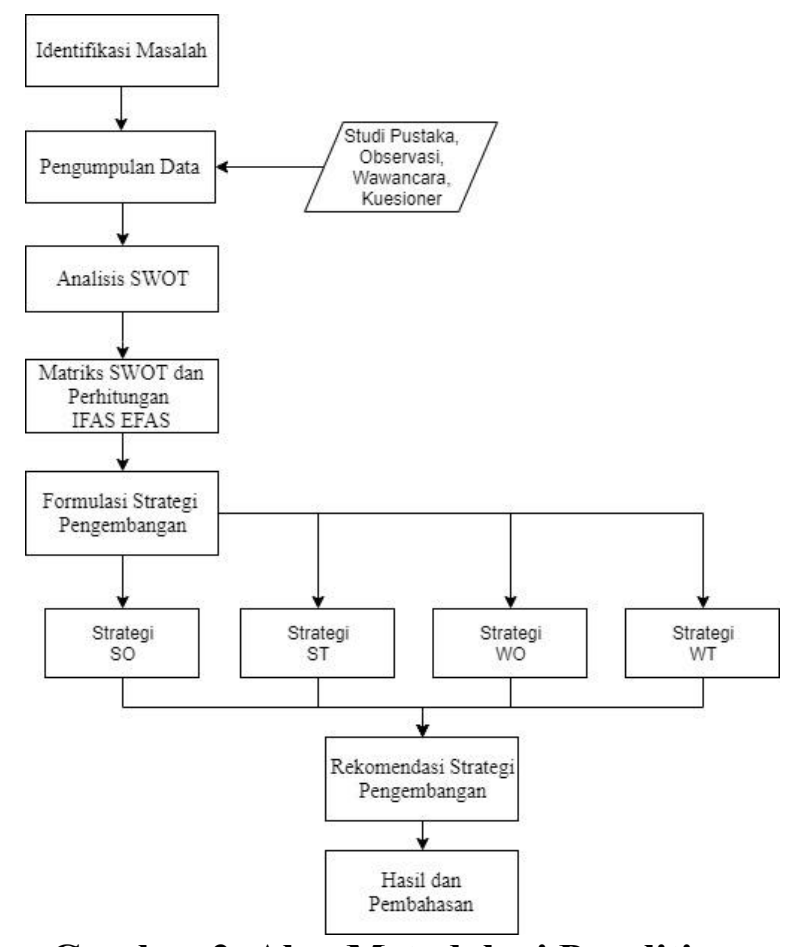

Gambar 2. Alur Metodologi Penelitian 


\subsection{Pengumpulan Data}

Pengumpulan data pada penelitian ini terbagai menjadi dua jenis, yaitu data sekunder dan primer.

1. Data Sekunder

Data sekunder merupakan data yang didapatkan dari studi pustaka seperti jurnal dan buku yang berkaitan dengan materi dalam penelitian ini. Adapun data sekunder pada penelitian ini yaitu:

a. Studi pustaka mengenai metode analisis SWOT, langkah-langkah menentukan IFAS dan EFAS, skala rating dan gambar diagram analisis SWOT.

2. Data Primer

Data primer merupakan data yang didapatkan langsung melalui pengamatan pada objek, yaitu UMKM Rumah Sayur. Metode yang dipakai untuk pengumpulan data primer yaitu:

a. Observasi, yaitu metode pengumpulan data dengan cara mengamati UMKM Rumah Sayur secara langsung, serta dokumen-dokumen yang berhubungan dengan masalah yang diteliti.

b. Wawancara, dilakukan tanya jawab langsung dengan pengelola UMKM Rumah Sayur sebagai responden mengenai faktor internal dan eksternal yang ada pada UMKM tersebut.

c. Kuesioner, digunakan dalam penelitian ini terdiri dari empat pertanyaan terkait faktor kekuatan, kelemahan, peluang, dan ancaman. UMKM Rumah Sayur sebagai sampel dan target responden yaitu pengelola UMKM seperti ketua komoditas, CMO, koordinator petani, dan bagian pemasaran. Hasil dari kuesioner ini digunakan untuk perhitungan matriks IFAS dan EFAS, yang kemudian disusun menjadi diagram SWOT untuk mengetahui ada di kuadran berapa dan strategi apa yang dapat dimanfaatkan oleh UMKM Rumah Sayur.

\section{HASIL DAN PEMBAHASAN}

\subsection{Hasil Penelitian}

Proses pengambilan keputusan strategis oleh perusahaan atau organisasi ditentukan oleh faktor internal dan eksternal. Faktor internal terdiri dari kekuatan (Strengths) dan kelemahan (Weakness). Sementara itu, faktor eksternal terdiri dari peluang (Opportunity) dan ancaman (Threat). Pada subbab ini disajikan hasil penerapan SWOT untuk evaluasi UMKM Rumah Sayur Lembang. Proses wawancara dengan pengelola UMKM Rumah Sayur, dan kuesioner yang digunakan dalam penelitian ini terdiri dari empat pertanyaan terkait faktor kekuatan, kelemahan, peluang, dan ancaman. Target responden yaitu pengelola UMKM Rumah Sayur. Didapatlah data sebagai berikut:

1. Kekuatan (Strengths)

a. Kualitas sayuran yang sangat bagus

b. Harga yang ditawarkan terjangkau

c. Sayuran terjamin kesegarannya karena proses pengemasan yang dilakuksan secara mendadak dan menyesuaikan dengan pesanan yang diterima

d. Perusahaan terus melakukan inovasi produk

2. Kelemahan (Weaknesses)

a. Aplikasi IT belum digunakan secara maksimal

b. Proses marketing yang kurang baik

c. Belum banyak yang mengetahui tentang Rumah Sayuran 
d. Komunikasi yang kurang baik, sehingga berdampak pada penanganan konsumen yang lama

3. Peluang (Opportunities)

a. Banyak komunitas yang ingin bekerja sama dengan UMKM Rumah Sayur

b. Perkembangan dan kemajuan teknologi informasi

c. Kepercayaan konsumen sangat besar/ tinggi terhadap kualitas produk yang ditawarkan

d. Tersedianya lahan pariwisata bagi konsumen

4. Ancaman (Threats)

a. Banyaknya pesaing/ kompetitor lain yang memiliki usaha sejenis

b. Kurangnya kompetensi pengelola sistem

c. Konsumen semakin sensitif terhadap harga

d. Perkembangan Teknologi Informasi yang sangat cepat

\subsection{Matriks SWOT}

Matriks di bawah ini merupakan penggambaran secara jelas mengenai penyesuaian antara kekuatan dan kelemahan dengan peluang dan ancaman dari suatu perusahaan. Matriks ini dapat menghasilkan 4 set kemungkinan alternatif strategis.

Tabel 2. Matriks SWOT UMKM Rumah Sayur

\begin{tabular}{|c|c|c|}
\hline EFAS & $\begin{array}{l}\text { STRENGHT (S) } \\
\text { 1. Kualitas sayuran yang sangat bagus } \\
\text { 2. Harga yang ditawarkan } \\
\text { terjangkau } \\
\text { 3. Sayuran terjamin kesegarannya } \\
\text { karena proses pengemasan yang } \\
\text { dilakuksan secara mendadak dan } \\
\text { menyesuaikan dengan pesanan yang } \\
\text { diterima } \\
\text { 4. Perusahaan terus melakukan inovasi } \\
\text { produk }\end{array}$ & $\begin{array}{l}\text { WEAKNESS (W) } \\
\text { 1. Aplikasi IT belum digunakan secara } \\
\text { maksimal } \\
\text { 2. Proses marketing yang kurang baik } \\
\text { 3. Belum banyak yang mengetahui } \\
\text { tentang Rumah Sayuran } \\
\text { 4. Komunikasi yang kurang baik, } \\
\text { sehingga berdampak pada } \\
\text { penanganan konsumen yang lama }\end{array}$ \\
\hline $\begin{array}{l}\text { OPPORTUNITI (O) } \\
\text { 1. Banyak komunitas yang ingin } \\
\text { bekerja sama dengan UMKM } \\
\text { Rumah Sayur } \\
\text { 2. Perkembang-an dan kemajuan } \\
\text { teknologi informasi } \\
\text { 3. Kepercayaan konsumen sangat } \\
\text { besar/ tinggi terhadap kualitas } \\
\text { produk yang ditawarkan } \\
\text { 4. Tersedianya lahan pariwisata } \\
\text { bagi konsumen }\end{array}$ & $\begin{array}{l}\text { STRATEGI SO } \\
\text { Dengan kualitas sayuran yang sangat } \\
\text { bagus, harga terjangkau, dan terus } \\
\text { dilakukan inovasi produk, jika } \\
\text { ditambah dengan pemanfaatan } \\
\text { teknologi informasi dan bekerja } \\
\text { sama dengan komunitas, maka } \\
\text { penjualan sayuran akan meningkat } \\
\text { dan memperluas pangsa pasar. }\end{array}$ & $\begin{array}{l}\text { STRATEGI WO } \\
\text { Banyaknya komunitas yang ingin } \\
\text { bekerja sama dapat membantu } \\
\text { memaksimalkan penggunaan dan } \\
\text { pengemban-gan aplikasi IT dan } \\
\text { komunikasi pada UMKM Rumah Sayur } \\
\text { sehingga meningkatkan waktu } \\
\text { penanganan konsumen, dan dengan } \\
\text { tersedianya lahan pariwisata juga } \\
\text { diharapkan dapat meningkatkan minat } \\
\text { beli konsumen }\end{array}$ \\
\hline $\begin{array}{l}\text { THREATS (T) } \\
\text { 1. Banyaknya pesaing/ kompetitor } \\
\text { lain yang memiliki usaha sejenis } \\
\text { 2. Kurangnya kompetensi } \\
\text { pengelola sistem } \\
\text { 3. Konsumen semakin sensitif } \\
\text { terhadap harga } \\
\text { 4. Perkembangan Teknologi } \\
\text { Informasi yang sangat cepat }\end{array}$ & $\begin{array}{l}\text { STRATEGI ST } \\
\text { Produk yang ditawarkan memiliki } \\
\text { kualitas yang bagus dengan harga } \\
\text { terjangkau dan terjamin } \\
\text { kesegarannya karena proses } \\
\text { pengemasan yang berkualitas dapat } \\
\text { menjadi marketing tersendiri bagi } \\
\text { UMKM Rumah Sayur ini yang akan } \\
\text { terus melakukan inovasi }\end{array}$ & $\begin{array}{l}\text { STRATEGI WT } \\
\text { Dengan seiringnya perkembangan } \\
\text { teknologi yang semakin maju dapat } \\
\text { digunkan sebagai sarana yang } \\
\text { membantu UMKM Rumah Sayur } \\
\text { dalam pengelolaan dan penjualan } \\
\text { poduk }\end{array}$ \\
\hline
\end{tabular}




\subsection{Perhitungan Matriks IFAS dan EFAS}

Berikut merupakan matriks IFAS (Internal Faktor Analisis Strategi) dan EFAS (Eksternal Faktor Analisis Strategi) dari hasil evaluasi faktor internal dan eksternal :

Tabel 3. Matriks EFAS (Eksternal Faktor Analisis Strategi ) UMKM Rumah Sayur

\begin{tabular}{|c|c|c|c|c|c|}
\hline \multirow{2}{*}{ No } & Eksternal Faktor & \multirow{2}{*}{ Jumlah } & \multirow{2}{*}{ Rating } & \multirow{2}{*}{ Bobot } & \multirow{2}{*}{$\begin{array}{c}\text { Bobot X } \\
\text { Rating }\end{array}$} \\
\hline & PELUANG & & & & \\
\hline 1 & $\begin{array}{l}\text { Banyak komunitas yang ingin bekerja } \\
\text { sama dengan UMKM Rumah Sayur }\end{array}$ & 19 & 3.8 & 0.13 & 0.49 \\
\hline 2 & $\begin{array}{l}\text { Perkembangan dan kemajuan teknologi } \\
\text { informasi }\end{array}$ & 15 & 3 & 0.10 & 0.3 \\
\hline 3 & $\begin{array}{l}\text { Kepercayaan konsumen sangat besar/ } \\
\text { tinggi terhadap kualitas produk yang } \\
\text { ditawarkan }\end{array}$ & 20 & 4 & 0.14 & 0.56 \\
\hline \multirow[t]{2}{*}{4} & $\begin{array}{l}\text { Tersedianya lahan pariwisata bagi } \\
\text { konsumen }\end{array}$ & 17 & 3.4 & 0.12 & 0.40 \\
\hline & TOTAL & & & & 1.75 \\
\hline \multirow{2}{*}{ No } & Eksternal Faktor & \multirow{2}{*}{ Jumlah } & \multirow{2}{*}{ Rating } & \multirow{2}{*}{ Bobot } & \multirow{2}{*}{$\begin{array}{r}\text { Bobot X } \\
\text { Rating }\end{array}$} \\
\hline & ANCAMAN & & & & \\
\hline 1 & $\begin{array}{l}\text { Banyaknya pesaing/ kompetitor lain yang } \\
\text { memiliki usaha sejenis }\end{array}$ & 19 & 3.8 & 0.13 & 0.49 \\
\hline 2 & Kurangnya kompetensi pengelola sistem & 17 & 3.4 & 0.12 & 0.40 \\
\hline 3 & $\begin{array}{l}\text { Konsumen semakin sensitif terhadap } \\
\text { harga }\end{array}$ & 16 & 3.2 & 0.11 & 0.35 \\
\hline \multirow[t]{2}{*}{4} & $\begin{array}{l}\text { Perkembangan Teknologi Informasi yang } \\
\text { sangat cepat }\end{array}$ & 15 & 3 & 0.10 & 0.3 \\
\hline & TOTAL & & & & 1.54 \\
\hline
\end{tabular}

Tabel 4. Matriks IFAS (Internal Faktor Analisis Strategi) UMKM Rumah Sayur

\begin{tabular}{|c|c|c|c|c|c|}
\hline \multirow{2}{*}{ No } & Internal Faktor & \multirow{2}{*}{ Jumlah } & \multirow{2}{*}{ Rating } & \multirow{2}{*}{ Bobot } & \multirow{2}{*}{$\begin{array}{r}\text { Bobot X } \\
\text { Rating }\end{array}$} \\
\hline & KEKUATAN & & & & \\
\hline 1 & Kualitas sayuran yang sangat bagus & 17 & 3.4 & 0.12 & 0.40 \\
\hline 2 & Harga yang ditawarkan terjangkau & 18 & 3.6 & 0.13 & 0.46 \\
\hline 3 & $\begin{array}{l}\text { Sayuran terjamin kesegarannya } \\
\text { karena proses pengemasan yang } \\
\text { dilakuksan secara mendadak dan } \\
\text { menyesuaikan dengan pesanan yang } \\
\text { diterima }\end{array}$ & 19 & 3.8 & 0.14 & 0.53 \\
\hline \multirow[t]{2}{*}{4} & $\begin{array}{l}\text { Perusahaan terus melakukan inovasi } \\
\text { produk }\end{array}$ & 17 & 3.4 & 0.12 & 0.35 \\
\hline & TOTAL & & & & 1.74 \\
\hline \multirow{2}{*}{ No } & Internal Faktor & \multirow{2}{*}{ Jumlah } & \multirow{2}{*}{ Rating } & \multirow{2}{*}{ Bobot } & \multirow{2}{*}{$\begin{array}{r}\text { Bobot X } \\
\text { Rating }\end{array}$} \\
\hline & KELEMAHAN & & & & \\
\hline 1 & $\begin{array}{l}\text { Aplikasi IT belum digunakan secara } \\
\text { maksimal }\end{array}$ & 19 & 3.8 & 0.14 & 0.53 \\
\hline 2 & Proses marketing yang kurang baik & 17 & 3.4 & 0.12 & 0.40 \\
\hline 3 & $\begin{array}{l}\text { Belum banyak yang mengetahui } \\
\text { tentang Rumah Sayuran }\end{array}$ & 14 & 2.8 & 0.10 & 0.28 \\
\hline \multirow[t]{2}{*}{4} & $\begin{array}{l}\text { Komunikasi yang kurang baik, } \\
\text { sehingga berdampak pada penanganan } \\
\text { konsumen yang lama }\end{array}$ & 14 & 2.8 & 0.10 & 0.28 \\
\hline & TOTAL & & & & 1.49 \\
\hline
\end{tabular}




\section{Keterangan}

- Responden 1 : Opik

$$
\text { (Ketua Pengelola) }
$$

- Responden 2 : Doni Hermanto

$$
\text { (CMO) }
$$

- Responden 3 : M Fuad Rahman

(Koordinator Petani)

- Responden 4 : Adjie Abdul Azis

(Pemasaran)

- Responden 5 : Ilham Taupikkurahman

(Pemasaran)

Setelah diketahui nilai IFAS dan EFAS, maka disusun diagram SWOT untuk mengetahui posisi UMKM Rumah Sayur. Untuk mencarinya dilakukan dengan mencari selisih IFAS dan EFAS.

Titik X (internal) $=$ kekuatan - kelemahan $=1.74-1.49=0.25$

Titik Y $($ eksternal $)=$ peluang - ancaman $=1.75-1.54=0.21$

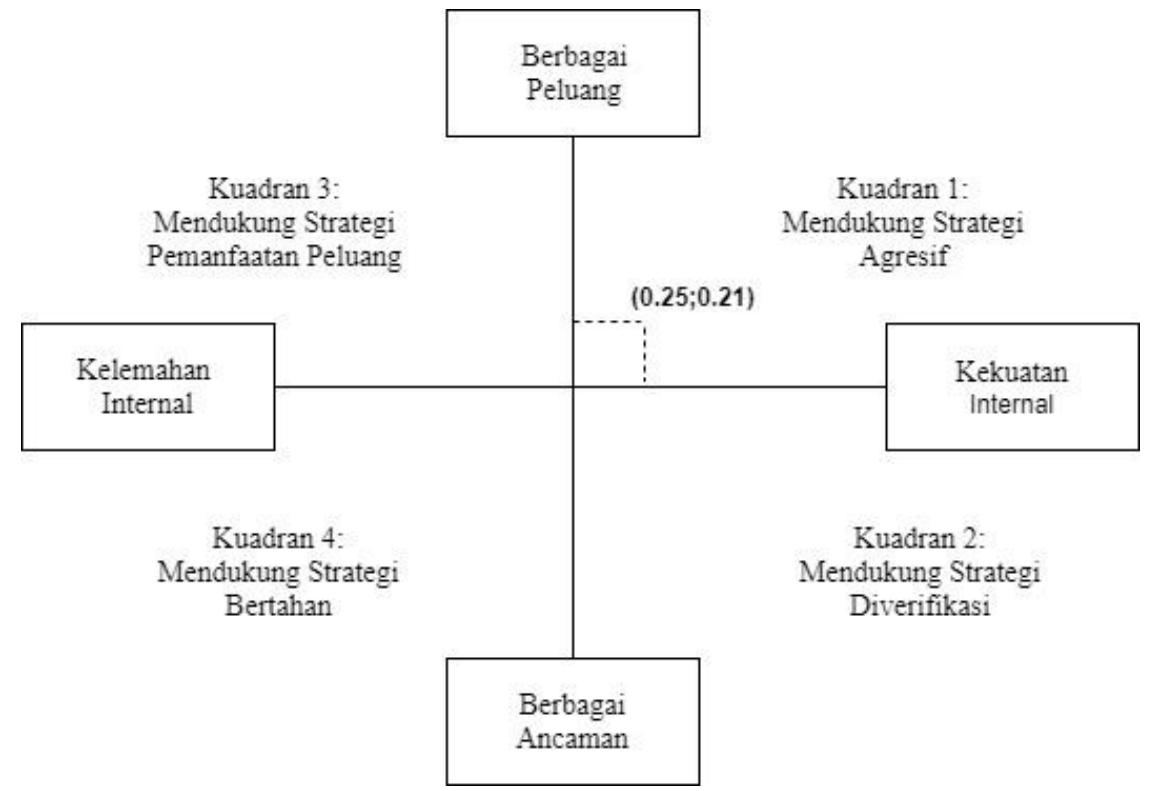

Gambar 3. Diagram SWOT UMKM Rumah Sayur

Berdasarkan analisis SWOT faktor internal dan eksternal, dalam perhitungan IFAS dan EFAS yang telah dilakukan, dapat diketahui dalam diagram analisis SWOT bahwa UMKM Rumah Sayur berada pada kuadran 1 yang berarti UMKM memiliki kekuatan dan peluang sehingga peluang yang ada dapat dimanfaatkan. Strategi yang harus diterapkan dalam kondisi ini adalah mendukung kebijakan pertumbuhan yang agresif (growth oriented strategy). Kekuatan yang dimiliki UMKM Rumah Sayur diantaranya produk yang dihasilkan memiliki kualitas yang sangat bagus serta harga yang ditawarkan terjangkau, dengan peluang diantaranya perkembangan teknologi informasi yang sudah sangat maju, serta banyak komunitas yang ingin bekerja sama dengan UMKM Rumah Sayur. Sehingga dengan memanfaatkan teknologi informasi yang sudah maju salah satunya dengan memakai teknologi e-commerce merupakan cara yang tepat untuk membuat UMKM Rumah Sayur lebih maju dan berkembang lagi. 


\section{SIMPULAN}

Dari hasil penelitian yang telah dilakukan, dan telah dijabarkan dalam bentuk diagram SWOT, Matriks SWOT dan Perhitungan IFAS (Internal Faktor Analisis Strategi) dan EFAS (Eksternal Faktor Analisis Strategi), dapat diambil kesimpulan tentang penerapan SWOT pada UMKM Rumah Sayur yaitu Hasil perhitungan pada tabel IFAS dan EFAS dengan perbandingan antara kekuatan dan kelemahan, perhitungan IFAS menunjukan bahwa Strenght (Kekuatan) lebih besar dari Weakness (Kelemahan). Sementara perhitungan EFAS menunjukan Opportunity (Peluang) lebih besar dari Threat (Ancaman), dengan demikian UMKM Rumah Sayur harus memilih dan menggunakan strategi agresif atau berkembang, dimana mencakup kondisi kekuatan dan peluang berada di posisi yang baik atau Strategi SO dimana kesiapan akan teknologi juga merupakan faktor yang paling penting dalam pendorong UMKM. Dengan begitu UMKM Rumah Sayur harus memiliki kualitas tenaga kerja yang baik atau bagus untuk menghadapi kesiapan teknologi tersebut, dan mengembangkan teknologi e-commerce yang berkualitas untuk mendukung pengelolaan dan penjualan produk pada UMKM Rumah Sayur.

\section{UCAPAN TERIMAKASIH}

Alhamdulillah, puji syukur selalu peneliti hantarkan kepada Allah SWT yang telah menganugerahkan rahmat, taufik dan berkah-Nya sehingga peneliti dapat menyelesaikan penelitian ini dengan baik. Peneliti juga ingin menyampaikan ucapan terimakasih yang tak terhingga kepada Civitas Universitas Adhirajasa Reswara Sanjaya, teman-teman, dan pihak terkait yang telah membantu proses penelitian ini berjalan.

\section{DAFTAR PUSTAKA}

[1] Y. R. Suci, "Perkembangan UMKM (Usaha Mikro Kecil dan Menengah) Di Indonesia," J. Ilm. Cano Ekon., vol. 6, no. 1, pp. 51-58, 2017.

[2] S. S. Utami, "Pengaruh Teknologi Informasi Dalam Perkembangan Bisnis Setyaningsih Sri Utami Fakultas Ekonomi Universitas Slamet Riyadi Surakarta," J. Akunt. dan Sist. Teknol. Inf., vol. 8, no. 1, pp. 61-67, 2010.

[3] A. Nurrohmah and F. Alfanur, "Adopsi E-Commerce Pada Usaha Mikro Dan Kecil Di Bandung ( Studi Kasus Subsektor Fesyen ) Adoption Of E-Commerce On Micro And Small Enterprise In Bandung ( Fashion Subsector Case Study ),” vol. 3, no. 2, pp. 1120-1127, 2016.

[4] M. N. Sasongko, K. Amaliah, and M. Arfian, "Analisis Kebutuhan Pada Perancangan Sistem Informasi Sebaran Usaha Mikro, Kecil Dan Menengah,” Pros. Semin. Nas. XI, pp. 108-112, 2016.

[5] K. Mariana and R. Lisda, "Sistem Informasi Berbasis Web Produk Unggulan Usaha Mikro Kecil dan Menengah (UMKM) di Kota Semarang," Pros. Semin. Nas. Multi Disiplin Ilmu Call Pap. Unisbank, pp. 978-979, 2015.

[6] J. Sutriosno, "Strategi Pengembangan Teknologi E-Commerce," J. Telemat. MKOM, Vol.3 No.2, Sept. 2011, vol. 3, no. 2, 2011.

[7] A. Hermawati et al., "Pendekatan Analisis SWOT Salah Satu Strategi Membangun Kinerja UMKM," in CIASTECH, 2019, no. Ciastech, pp. 29-38.

[8] P. Anggraeni, M. K. Mawardi, F. I. Administrasi, and U. Brawijaya, "Analisis swot pada umkm keripik tempe amel malang dalam rangka meningkatkan daya saing perusahaan," vol. 43 , no. 1. 
[9] A. Saputra, "Analisis dan rekomendasi strategi e-commerce pada usaha kecil menengah batik sokaraja," J. Pro B isnis, vol. 10, no. 1, pp. 19-35, 2017.

[10] Z. Nisak, “Analisis SWOT Untuk Menentukan Strategi Kompetitif,” 2004.

[11] A. Maskur, S. Nagari, Patria, and Nasfi, "SWOT Analisis Dan Matrik SWOT Analisis Dalam Rangka Pemasaran Produk Pendanaan Bank (Studi PT. BPR RANGKIANG AUR)Hughes, Rebecca," J. Point Equilib. Manaj. Akunt., vol. 2, no. 1, pp. 13-28, 2020.

[12] S. Adhi Wibowo, "Penerapan Analisis SWOT Dalam Menentukan Strategi Pengembangan Sistem Informasi STIKOM Yos Sudarso Purwokerto," J. Chem. Inf. Model., vol. 53, no. 9, pp. 1689-1699, 2013.

[13] R. D. Komala and T. I. Wijaksana, "Analisis Strategi Pemasaran Menggunakan Analisis SWOT Studi Pada Eduplex Coworking Space Bandung," in e-Proceeding of Management, 2019, vol. 16, no. 1, p. 920.

[14] D. Oreski, "Strategy development by using SWOT - AHP," TEM J., vol. 1, no. 4, 2012.

[15] A. Hardiyanto, I. I. Soejanto, and I. Berlianty, "Analisis strategi pembangunan desa wisata di sentra pengrajin keris," OPSI, vol. 11, no. 1, 2018.

[16] I. Salamah and RD Kusumanto, "JURNAL RESTI Faktor - Faktor Pemanfaatan Teknologi Informasi,” RESTI, vol. 1, no. 3, pp. 177-182, 2017.

[17] R. F. Oktaviani, "Peran Kemajuan Teknologi Ecommerce Untuk Percepatan Keberhasilan Kinerja Dengan Penerapan Strategi Pemasaran UKM (Kasus UKM Sektor Fashion Di Wilayah Jakarta)," J. Ekon. dan Manaj., vol. 6, no. 2, pp. 176-195, 2017.

[18] S. Noor, "Penerapan Analisis SWOT Dalam Strategi Pengembangan Museum Brawijaya Sebagai Salah Satu Aset Sejarah Kota Malang," INTEKNA, no. 2, 2014. 